\title{
Relevance of reproductive correlates in response of diamondback moth (Lepidoptera: Plutellidae) to plant quality
}

\author{
M. Soufbaf,' Y. Fathipour, ${ }^{1}$ M.P. Zalucki, ${ }^{2}$ J. Karimzadeh ${ }^{3}$ \\ ${ }^{1}$ Department of Entomology, Faculty of Agriculture, Tarbiat Modares University, Tehran, Iran; \\ 2School of Biological Sciences, The University of Queensland, St. Lucia, Queensland, Australia; \\ ${ }^{3}$ Department of Plant Protection, Isfahan Research Centre for Agriculture and Natural Resources, \\ Isfahan, Iran
}

\begin{abstract}
To study the relationships between leaf nitrogen and the reproductive potential of diamondback moth, all reproductive parameters of this pest raised on two canola cultivars were evaluated. A standardized regression coefficient $(\beta)$ was used as an index for nitrogen-reproduction relationship strength. The only difference between net fecundity rate and net fertility rate is $h_{x}$ 's effect, but the difference in their standardized regression coefficients was not significant $[\beta=+0.934$ $\left(\mathrm{R}^{2}=0.87, \mathrm{~F}_{1,4}=27.34, \mathrm{P}=0.006\right)$ and $\beta=+0.922\left(\mathrm{R}^{2}=0.85, \mathrm{~F}_{1,4}=22.825\right.$, $\mathrm{P}=0.009)$ ]. Accordingly, gross fecundity rate and gross fertility rate differ only in $h_{x}$ 's effect, but the difference in standardized regression coefficients again was not significant $\left[\beta=0.895\left(R^{2}=0.8, F_{1,4}=16.159\right.\right.$, $\left.\mathrm{P}=0.016)-0.890 \quad\left(\mathrm{R}^{2}=0.79, \mathrm{~F}_{1,4}=15.266, \mathrm{P}=0.017\right)=0.005\right]$. As gross fecundity rate differs from net fecundity rate only in midpoint survivorship $\left(L_{x}\right)$ 's effect, it is understood that survivorship could affect the
\end{abstract}

Correspondence: Yaghoub Fathipour, Department of Entomology, Faculty of Agriculture, Tarbiat Modares University, P.0. Box 14115-336, Tehran, Iran. Tel.: +98.21.48292301 - Fax: +98.21 .48292200 .

E-mail: fathi@modares.ac.ir

Key words: fecundity, hatch rate, nitrogen, Plutella xylostella, survivorship.

Funding: this work was funded by Tarbiat Modares University, which is greatly appreciated.

Contributions: MS, JK, YF, designed the experiments; MS, performed the experiments and prepared the manuscript; MS, performed statistical analyses; YF, MPZ, provided editorial advice.

Received for publication: 29 April 2013.

Revision received: 6 June 2013.

Accepted for publication: 12 June 2013.

(c) Copyright M. Soufbaf et al., 2013

Licensee PAGEPress, Italy

Journal of Entomological and Acarological Research 2013; 45:e10

doi:10.4081/jear.2013.e10

This article is distributed under the terms of the Creative Commons Attribution Noncommercial License (by-nc 3.0) which permits any noncommercial use, distribution, and reproduction in any medium, provided the original author(s) and source are credited. plant nitrogen-fecundity relation considerably (standardized coefficients difference $=0.044$ ) and could be a critical parameter in insectplant interactions. But, the terms of reproductive parameters, i.e. $L_{x}$ and $h_{x}$, showed the same effect on the strength of nitrogen-fecundity regression statistically, even though $L_{x}$ has been selected frequently by many researchers as an important fitness correlate. Measuring the hatch rate could be recommended in trophic interactions studies due to its being easier to apply, more robust, and quicker to accomplish than measurement of survivorship; however, it is important as an indicator in combination with brood size for determining the initial population size of an insect herbivore.

\section{Introduction}

Fitness of non-feeding adult herbivorous insects, especially their reproductive potential, is frequently affected by plant chemical or physical quality (Awmack \& Leather, 2002; Moreau et al., 2006; Ode, 2006). The effects of plant quality on insect performance correlates such as reproduction have frequently been noted by insect researchers (Joern \& Behmer, 1998). Host plant quality affects many life history characteristics of herbivorous visitors through effects on their growth rate, resistance to diseases, reproduction (Price et al., 1980) and population fluctuations due to reproductive variation, survival, and development of the herbivore (Walde, 1995). Harcourt (1963) suggested that nitrogen was important in diamondback moth population dynamics in the 1960s, and White (1993) has been a strong advocate for years. Primary plant metabolites, including nitrogen, which has been shown to strongly affect the feeding and growth of insect herbivores (Smith \& Northcott, 1951; Mattson, 1980; White, 1984; Agrawal, 2004; Soufbaf et al., 2012), have been paid less attention compared with studies on secondary plant metabolites' effects on insect performance (Harvey, 2005; Ode, 2006).

There is a voluminous literature on the effect of plant cultivar or species on herbivore reproduction (Begum et al., 1996; Awmack \& Leather, 2002; Sarfraz et al., 2007, 2009); but the potential relationships between reproduction and plant primary chemistry have not been well studied. Moreover, studies that examine the effect of plant quality on insect performance mainly use synthetic nitrogenous fertilizers, which could inevitably raise plant biomass as plant quality is improved; therefore, the effects of natural plant quality have not been studied per se. Fecundity is the number of eggs laid by an individual insect, while fertility is the number of viable offspring produced (Awmack \& Leather, 2002). Accordingly, the number of eggs hatched refers to the difference between fecundity and fertility in such insects. One of the reproductive strategies taken by a female insect encounter- 
ing a low-quality host plant is to lay a large number of low-quality eggs (Rossiter et al., 1993). Certainly, a proportion of these eggs have a very low chance of becoming viable offspring under natural conditions. The ratio of eggs surviving to total eggs laid refers to egg hatchability, which is interestingly ignored by many researchers in the area of host plant quality-insect herbivore reproduction studies. Even so, Awmack \& Leather (2002) in their review on such studies, which categorized them according to the measured insect fitness correlates, did not define the share of fertility or egg mortality against the $7 \%$ share of fecundity achieved. Obviously, egg hatch rate might bear considerably on the reproductive success of an insect herbivore. However, in similar studies on parasitoids, for instance, Harvey (2005) demonstrated that in comparing the allocation of limited host resources to different fitness functions, less attention has been paid to developmental time and survival that may vary with host quality, in comparison with body size, which has been considered as the most prominent fitness measure in predictive models.

Here, the strength and importance of the relationship between the primary plant metabolite, nitrogen, and reproductive potential of the diamondback moth were examined. To this end, two out of ten possible Brassica napus (canola) cultivars, $\mathrm{SLM}_{046}$ and $\mathrm{RGS}_{003}$, were selected to represent high- and low-quality host plants. These have previously been shown to differ in nitrogen contents, and to significantly affect the biology and life table parameters of diamondback moth, Plutella xylostella L. (Lepidoptera: Plutellidae) (Soufbaf et al., 2010a, 2010b, 2012), which is the most important pest of cruciferous crops to have developed resistance to all classes of insecticides (Sarfraz et al., 2007). This insect was studied after four generations were allowed to feed on the respective plant cultivars, by which time it was hypothesized that the different host plant qualities would have been manifested in subsequent diamondback moth generations. As excised leaves were used as hosts in this trial, diamondback moth was supplied only with fixedquality plant material, which could inevitably just show different nutritional quality of plants (i.e., the potential effects of volatiles from live plants were removed; therefore, the herbivores were not allowed to express a preference in selecting host plants as an oviposition substrate in this study). Nitrogen and water have been recognized by many researchers as the most important nutritional elements (Coley et al., 2006); therefore, the quality in question was determined by analyzing nitrogen as one of the most important plant nutrients, and then relationships were explored between this plant quality index and the reproductive potential of diamondback moth by using regression analysis.

One of the enduring challenges in insect fitness studies is in selecting the proper insect fitness correlates that show the greatest relevance to insect success in response to descriptive variables such as plant quality. Therefore, in a cause-and-effect context, the relative importance of two fitness correlates, including $L_{x}$ and $h_{x}$, was explored, considering that their relevance to reproductive parameters has been demonstrated mathematically by earlier researchers (Carey, 1993). In this study, we attempt to show that egg hatch rate is not less relevant than insect survival in host plant quality-insect herbivore reproduction interactions, despite the fact that it is not cited in any of the 170 studies in the literature survey by Awmack \& Leather (2002), compared with 26 records of these 170 studies that focus on insect survival.

\section{Materials and methods}

Diamondback moth larvae and pupae were collected from cabbage grown in the horticultural fields of the University of Tehran. Subcolonies of the herbivore were established on two plant cultivars separately and were maintained under constant environmental conditions at $25 \pm 2{ }^{\circ} \mathrm{C}, 60 \pm 5 \%$ relative humidity, and $16: 8 \mathrm{~h} \mathrm{~L} / \mathrm{D}$ for more than four generations. To assess the effect of different plant cultivars on the reproductive potential of diamondback moth, 20 newly emerged females from each plant cultivar were placed individually in ventilated plastic containers $(15 \times 20 \mathrm{~cm})$ and paired with males from the same plant cultivar. A leaf from each respective plant cultivar was placed in each container, and was replaced daily. The number of eggs laid was recorded daily until death of the last female. To prevent the leaf from wilting, the petiole was wrapped with cotton wool soaked in water. Following the methods of Carey (1993), the reproductive potential parameters were calculated. Leaf tissue from each plant was analyzed for nitrogen $(\mathrm{N})$ content. Leaves of each plant cultivar were dried at $55^{\circ} \mathrm{C}$ for $12 \mathrm{~h}$ and the nitrogen content of the dried leaves was measured using the Kjeldahl method (Karla, 1998). Dried leaf samples of each plant cultivar were obtained from ten different plants, to account for variability in nitrogen quality and quantity among individual plants (Mattson, 1980), and three replicates were run for each plant cultivar.

\section{Statistical analysis}

All data obtained from measurements on the two plant cultivars were subjected to the Kolmogorov-Smirnov test for normality before analysis. A multivariate general linear model was used to demonstrate the effects of plant cultivar on the reproductive potential parameters of the herbivore. Relationships between leaf tissue nitrogen content and reproduction parameters of the herbivore were assessed using linear regression analysis. To determine the strength of the relationship between these two quantities, the product moment correlation coefficients (e.g. Pearson's coefficient) would be suitable tools to employ; however, the necessary condition for use of such correlations is that linear regression between two variables must be significant. The linear regression strength using a standardized coefficient $(\beta)$ was applied as an index for assessing the strength of plant nitrogen and moth reproduction trade-off. As all reproductive parameters are inter-related, their formulae are different by just one or two terms (Table 1). It was hypothesized that quantified differences among the parameters in their relationship with plant nitrogen could be related to the terms in question. For instance, gross fecundity rate and gross fertility rate are different in the term $h_{x}$, and net fecundity rate and gross fecundity rate vary in $L_{x}$. These different terms can be protagonists in creating the differences among the closely related parameters. Therefore, differences between standardized regression coefficients $(\beta)$ were assumed to be related to the terms in question. All statistical analyses were performed using SPSS 16 (SPSS ver. 2008, IBM Corp., Chicago, IL USA).

Table 1. Reproductive parameters and their formulae measured in this study after Carey (1993).

\begin{tabular}{|c|c|}
\hline Reproductive parameters & Formula \\
\hline GRR & $\sum_{x=\alpha}^{\beta} m_{x}$ \\
\hline Gross fecundity rate & $\sum_{x=\alpha}^{\beta} M_{x}$ \\
\hline Gross fertility rate & $\sum_{x=\alpha}^{\beta} h_{x} M_{x}$ \\
\hline Net fecundity rate & $\sum_{x=g}^{B} L_{x} M_{x}$ \\
\hline Net fertility rate & $\sum_{x=\rho}^{\beta} L_{x} h_{x} M_{x}$ \\
\hline
\end{tabular}

GRR, gross reproductive rate. $\alpha$ is the day on which the oviposition period begins, and $\beta$ is the last day of oviposition period; $m_{x}$ is average number of female eggs laid by each female during $x$ to $x+1$ age interval; $M_{x}$ represents the mean number of total eggs laid by each female during $\times$ to $\times+1$ age interval; $h_{x}$ represents the hatch rate; $L_{x}$ represents the mid-point survivorship of diamondback moths from age $\times$ to $x+1$. 


\section{Results}

The canola cultivar $\mathrm{SLM}_{046}$ showed a significantly higher value of leaf nitrogen content than the other host plant, $\mathrm{RGS}_{003}(5.1$ and $1.6 \%$ for $\mathrm{SLM}_{046}$ and $\mathrm{RGS}_{003}$, respectively) ( $\left.\mathrm{T}=40.86, \mathrm{df}=2, \mathrm{P}=0.001\right)$.

All reproductive parameters, including gross reproductive rate (GRR), gross fecundity rate, gross fertility rate, net fecundity rate, and net fertility rate, differed between the two plant cultivars (Table 2). For individuals reared on $\mathrm{RGS}_{003}$, parameters were lower than those on $\mathrm{SLM}_{046}$ (Table 2). There were strong relationships between nitrogen as the primary metabolite and all reproductive parameters of the herbivore (Table 3 , Figure 1). The plant nitrogen and the net fecundity rate of diamondback moth showed the strongest correlation measured in the current study $(\beta=+0.934)$, while plant nitrogen and the gross fecundity rate of diamondback moth showed a lower relationship $(\beta=+0.890)$ (Table 3, Figure 1).

The difference in standardized regression coefficients of net fecundity rate and net fertility rate was 0.012 , and the $95 \%$ confidence interval (CI) for their unstandardized $\beta$ overlapped (Table 3, Figure 1). The difference in standardized regression coefficients of gross fecundity rate and gross fertility rate was 0.005 (Table 3 , Figure 1). The standardized regression coefficients difference between gross fecundity rate and net fecundity rate was 0.044 .

\section{Discussion and conclusions}

Insect herbivores feeding on host plants of lower quality in components such as nitrogen characteristically show lower fecundity (Mattson, 1980; Awmack \& Leather, 2002; Chen et al., 2004). Diamondback moths laid more eggs on $\mathrm{SLM}_{046}$ than RGS $\mathrm{S}_{003}$ under the same environmental conditions. SLM $_{046}$ was the most suitable host plant for diamondback moth among ten tested canola cultivars (Soufbaf et al., 2010a, 2010b). This could be related to the high level of natural nitrogen available in the plant cultivar $\mathrm{SLM}_{046}$, so diamondback moth produced more eggs on this plant cultivar, which satisfied its nitrogen needs in a shorter period (Soufbaf et al., 2012). Similarly, diamondback moth was more abundant in high-nitrogen treatments than in lownitrogen treatments in a field study (Fox et al., 1990); however, in that study nitrogenous fertilizer was used to study plant quality.

All reproductive parameters, including GRR, gross fecundity rate, gross fertility rate, net fecundity rate, and net fertility rate, differed significantly between the two plant cultivars in this study. These parameters for individual moths reared on $\mathrm{RGS}_{003}$ were lower compared with those on $\mathrm{SLM}_{046}$. There were strong relationships between nitrogen as the primary metabolite and all reproductive parameters of the herbivore. Plant nitrogen and net fecundity rate of diamondback moth showed the strongest correlation $(\beta=+0.934)$, while plant nitro-

Table 2. Analysis from the reproductive potential parameters of Plutella xylostella (Lepidoptera: Plutellidae) on two canola cultivars. A multivariate general linear model approach was used to assay changes in all parameters between cultivars.

\begin{tabular}{lccccc} 
Canola cultivar & SLML46 & RGS & Type III sum of squares & df & F \\
Reproductive parameters & & $120.05 \pm 7.98$ & 9962.568 & 1,4 & $27.12^{* *}$ \\
GRR & $227.0 \pm 10.9$ & $243.9 \pm 14.3$ & $21,252.235$ & 1,4 & 1,4 \\
Gross fertility rate & $403.8 \pm 19.4$ & $178.4 \pm 10.7$ & $22,429.991$ & 1,4 & $24.81^{* *}$ \\
\hline Net fertility rate & $310.4 \pm 12.1$ & $264.9 \pm 15.5$ & $23,006.103$ & 1,4 & $16.16^{*}$ \\
Gross fecundity rate & $430.0 \pm 20.6$ & $176.28 \pm 9.88$ & $31,042.355$ & $-1.17^{* *}$ \\
\hline Net fecundity rate & $330.6 \pm 12.9$ & $92.06 \%$ & - & - &
\end{tabular}

df, degree of freedom; GRR, gross reproductive rate. Data represented in first two columns are mean \pm SE of measured parameters on respective canola cultivar. ${ }^{*}, * *, * * *$ represent significant levels at $\mathrm{P}<0.05, \mathrm{P}<0.01$, and $\mathrm{P}<0.001$, respectively.

Table 3. Statistics of linear regression relationships between plant nitrogen and the reproductive parameters of Plutella xylostella L. (Lepidoptera: Plutellidae).

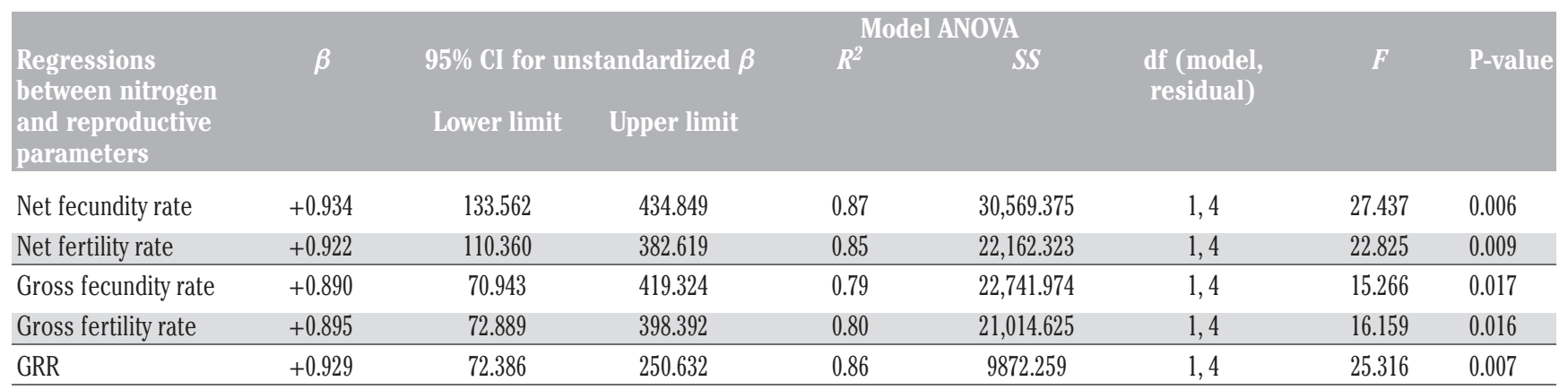

ANOVA, analysis of variance; $\mathrm{CI}$, confidence interval; df, degree of freedom; GRR, gross reproductive rate. 



Figure 1. Regression lines with $95 \%$
confidence intervals for regression
and population (long dashed and
short dashed lines around the regres-
sion line (solid line), respectively). A-
E) Linear fit of gross reproductive
rate (GRR), gross fertility rate, net
fertility rate, net fecundity rate and
gross fecundity rate of Plutella
xylostella (Lepidoptera: Plutellidae)
versus canola leaves nitrogen under
fixed environmental condition.

gen and gross fecundity rate showed the weakest relationship $(\beta=+0.890)$.

Net fecundity rate represents the product of the mean number of total eggs laid by each female during the $\mathrm{x}$ to $\mathrm{x}+1$ age interval, and midpoint survivorship, without considering egg hatch rate. Egg survival, which is manifested in hatch rate $\left(h_{x}\right)$, seems not to be a critical term in nitrogenfecundity relationship strength, as the only difference between net fecundity rate and net fertility rate is $h_{x}$, but the difference in their standardized regression coefficients is not significant $(+0.934$ and +0.922$)$, and the $95 \%$ CI for their unstandardized $\beta$ show overlap. Accordingly, gross fecundity rate and gross fertility rate formulae differ only in $h_{x}$ (Table 1), but the difference in standardized regression coefficients is again not significant $(0.895-0.890=0.0-5)$. As gross fecundity rate formulae only differ from net fecundity rate formulae in the midpoint survivorship term $\left(L_{x}\right)$, the first result is that the noted survivorship could affect the plant nitrogen-fecundity relationship considerably (standardized regression coefficients difference: $0.934-0.890=0.044$ ) and might be a critical parameter among insect fitness parameters in insect-plant interactions studies, as emphasized by many researchers (Harvey, 2005; Gols et al., 2008). But $95 \%$ CI for unstandardized $\beta$ (slope of regression line) for regressions among each reproductive parameter and nitrogen revealed that discriminate terms, i.e. $L_{x}$ and $h_{x}$, have the same effect on the strength of the nitrogen-fecundity regression statistically, although the effect of $L_{x}$ was nearly 8.8 times that of the $h_{x}$ effect.

In several herbivorous insects, measurements of body size and allometric quantities (e.g., total body weight/length of costal vein) have been shown to be robustly correlated with fecundity (Klingenberg \& Spence, 1997; Awmack \& Leather, 2002). Under similar nutritional requirements of both juvenile and adult, fecundity could be predicted by developmental rates, as reproductive rates could be supported by plants as are growth rates (Awmack \& Leather, 2002). However, as fecundity is not always a predictor of viable offspring, measures of egg hatch rate might be a more reliable indicator of the effects of host plant quality on herbivore fecundity than survival rates in both the juvenile and adult. This study first demonstrated that there was a strong positive relationship between nitrogen and the reproductive potential of diamondback moth. This could in turn emphasize the nutritional importance of nitrogen in the reproduction of the herbivore and thus in its population growth ability. Moreover, nitrogen contents in canola leaf tissues appeared to be strong positive predictors for reproductive potential of diamondback moth. Second, egg-adult survivorship and egg hatch rate showed the same relevance in plant chemistry-insect herbivore interactions. Therefore, measurement of egg hatch rate could be recommended in trophic interaction studies due to its being easier to apply, more robust, and quicker to accomplish than measurement of total survivorship.

\section{References}

AGRAWAL A., 2004 - Plant defense and density dependence in the population growth of herbivores. - Am. Nat. 164: 113-120.

AWMACK C.S., LEATHER S.R., 2002- Host plant quality and fecundity in herbivorous insects. - Annu. Rev. Entomol. 47: 817-844.

BEGUM S., TSUKUDA S.R., FUJISAKI K., NAKASUJI F., 1996 - The effects of wild cruciferous host plants on morphology, reproductive performance and flight activity in the diamondback moth, Plutella xylostella (Lepidoptera: Yponomeutidae). - Res. Popul. Ecol. 38: 257-263. 
CAREY J.R. 1993 - Applied demography for biologists with special emphasis on insect. - Oxford University Press, New York: 166.

CHEN Y.Z., LIN L., WANG C.W., YEH C.C., HWANG S.Y., 2004 - Response of two Pieris (Lepidoptera: Pieridae) species to fertilization of a host plant. - Zool. Studies. 43: 778-786.

COLEY P.D., BATEMAN M., KURSAR T., 2006 - The effects of plant quality on caterpillar growth and defense against natural enemies. Oikos. 115: 219-228.

FOX L.R., LETOURNEAU D.K., EISENBACH J., NOUHUYS S.V., 1990 Parasitism rates and sex ratios of a parasitoid wasp: effects of herbivore and plant quality. - 0ecol. 83: 414-419.

GOLS R., BUKOVINSZKY T., VAN DAM N.M., DICKE M., BULLOCK J.M., HARVEY J.A., 2008 - Performance of generalist and specialist herbivores and their endoparasitoids differs on cultivated and wild Brassica populations. - J. Chem. Ecol. 34: 132-143.

HARCOURT D.G., 1963 - Mortality factors in the population dynamics of the diamondback moth, Plutella maculipennis (Curt) (Lep.: Plutellidae). - Mem. Entomol. Soc. Can. 32: 55-66.

HARVEY J.A., 2005 - Factors affecting the evolution of development strategies in parasitoid wasps: the importance of functional constraints and incorporating complexity. - Entomol. Exp. Appl. 117: 1-13.

JOERN A., BEHMER S.T., 1998 - Impact of diet quality on demographic attributes in adult grasshoppers and the nitrogen limitation hypothesis. - Ecol. Entomol. 23: 174-184.

KARLA Y.P., 1998 - Reference methods for plant analysis, soil and plant analysis. Council, Inc. - CRC Press, Boca Raton, FL: 191.

KLINGENBERG C.P., SPENCE J.R., 1997 - On the role of body size for life-history evolution. - Ecol. Entomol. 22:55-68.

MATTSON W.J., 1980 - Herbivory in relation to plant nitrogen content. - Annu. Rev. Ecol. Syst. 11: 119-161.

MOREAU J., BENREY B., THIERY D., 2006 - Assessing larval food quality for phytophagous insects: are the facts as simple as they appear? - Funct. Ecol. 20: 592-600.

ODE P.J., 2006 - Plant chemistry and natural enemy fitness: effects on herbivore and natural enemy interactions. - Annu. Rev. Entomol. 51: $163-185$.

PRICE P.W., BOUTON C.E., GROSS P., MCPHERON B.A., THOMPSON
J.N., WEIS A.E., 1980 - Interactions among three trophic levels: Influence of plants on interactions between insect herbivores and natural enemies. - Annu. Rev. Ecol. Syst. 11: 41-65.

ROSSITER M.C., COX-FOSTER D.L., BRIGGS M.A., 1993 - Initiation of maternal effects in Lymantria dispar-genetic and ecological components of egg provisioning. - J. Evol. Biol. 6:577-90.

SARFRAZ R.M., DOSDALL L.M., KEDDIE A.B., 2007 - Resistance of some cultivated brassicaceae to infestations by Plutella xylostella (Lepidoptera: Plutellidae). - J. Econ. Entomol. 100: 215-224.

SARFRAZ R.M., DOSDALL L.M., KEDDIE A.B., 2009 - Bottom-up effects of host plant nutritional quality on Plutella xylostella (Lepidoptera: Plutellidae) and top-down effects of herbivore attack on plant compensatory ability. - Eur. J. Entomol. 106: 583-594.

SMITH D.S., NORTHCOTT F.E., 1951 - The effects on the grasshopper, Melanoplus mexicanus mexicanus (Sauss.) (Orthoptera: Acrididae), of varying the nitrogen content in its food plant. - Can. J. Zool. 29: 297-30.

SOUFBAF M., FATHIPOUR Y., KARIMZADEH J., ZALUCKI M.P., 2010a Bottom-up effect of different host plants on Plutella xylostella (Lepidoptera: Plutellidae): a life-table study on canola. - J. Econ. Entomol. 103: 2019-2027.

SOUFBAF M., FATHIPOUR Y., KARIMZADEH J., ZALUCKI M.P., 2010b Development and age-specific mortality of diamondback moth on Brassica host plants: Pattern and causes of mortality under laboratory conditions. - Ann. Entomol. Soc. Am. 103: 574-579.

SOUFBAF M., FATHIPOUR Y., ZALUCKI M.P., HUI C., 2012- Importance of primary metabolites in canola in mediating interactions between a specialist leaf-feeding insect and its specialist solitary endoparasitoid. - Arthropod. Plant Int. 6: 241-250.

WALDE S.J., 1995 - How quality of host plant affects a predator-prey interaction in biological control. - Ecol. 76: 1206-1219.

WHITE T.C.R., 1984 - The abundance of invertebrate herbivores in relation to the availability of nitrogen in stressed food plants. - Oecol. 63: $90-105$

WHITE T.C.R., 1993 - The inadequate environment: nitrogen and the abundance of animals. -Springer-Verlag, London: 425. 